\title{
Cutaneous nocardiosis complicating management of Crohn's disease with infliximab and prednisone
}

\author{
Sheldon M. Singh, Neil V. Rau, Lawrence B. Cohen, Howard Harris
}

ß See related article page 1045

Abstract

INFLIXIMAB IS A CHIMERIC ANTI-TUMOUR NECROSIS FACTOR- $\alpha$ antibody that is efficacious in treating Crohn's disease. However, its immunomodulatory properties increase susceptibility to opportunistic infections. We present a case of cutaneous Nocardia infection in a patient who was taking infliximab for Crohn's disease. The case illustrates the challenges in the diagnosis and management of this disease and serves as a reminder of the complications associated with the use of immunomodulatory agents.

CMAJ 2004;171(9):1063-4

A 45-year-old HIV-negative man with fistulous Crohn's disease had a history of inadequate disease control despite ongoing prednisone therapy. $\mathrm{He}$ had previously taken budesonide, mesalamine, ciprofloxacin and metronidazole in attempts to induce remission of his inflammatory bowel disease. The patient was born in Canada and, other than a 1-week holiday to Mexico 10 years before presentation, had travelled only locally. He denied a family history of tuberculosis, and he had never worked in a health care facility. Infliximab was introduced, and the patient received 3 infusions of $5 \mathrm{mg} / \mathrm{kg}$ at baseline and 2 and 6 weeks later. After he received his third infusion, prednisone was tapered to $40 \mathrm{mg}$ at a rate of $5 \mathrm{mg}$ weekly. One month after the third infusion, in February 2000, he reported multiple erythematous papulopustular lesions on his right leg (Fig. 1). There was no associated lymphadenopathy, cough, shortness of breath, fever or constitutional symptoms. He denied a history of insect bites, but in November 1999 he had received cuts to his right leg from a metal blade when at work. He had not immersed the leg in a whirlpool or swimming pool around the time of the leg injury. The patient continued to receive further infliximab infusions (at weeks 12 and 18 after baseline), and the lesions were treated with cloxacillin for suspected Staphylococcus aureus infection. Since improvement was minimal, a skin biopsy was performed in July 2000. Granulomatous inflammation was present, and acid-fast bacilli were visualized (Fig. 2). Cultures sent for mycobacteriology and mycology were incubated at $35^{\circ} \mathrm{C}$ for 8 weeks, but the re- sults from the mycobacteriology culture proved negative. A polymerase chain reaction assay for Mycobacterium tuberculosus was also negative. A clinical diagnosis of M. marinum infection was made, and the patient's antibiotic regimen was changed to minocycline. A tuberculin skin test was not performed; since the patient was immunocompromised, a negative result would not have excluded the disease. A chest radiograph appeared normal.

The patient failed to respond to the minocycline therapy, and he was referred for infectious disease consultation in October 2000. The infliximab infusions were discontinued, and 2 more skin biopsies were performed, with acid-fast bacilli visualized in both specimens. The patient was given trimethoprim-sulfamethoxazole, and his lesions began to heal slowly but progressively.

Acid-fast bacilli were recovered from the second set of biopsies, and specific instructions were given to incubate the cultures at $30^{\circ} \mathrm{C}$ and $35^{\circ} \mathrm{C}$ to ensure that $M$. marinum, if present, would be detected. Again, the cultures failed to recover organisms. The laboratory, using polymerase chain reaction restriction analysis of the 439-base pair segment of the gene encoding a $65-\mathrm{kDa}$ heat shock protein, ${ }^{1}$ identified the presence of Nocardia species. Nevertheless, Nocardia organisms still could not be recovered in culture, and therefore final speciation could not be performed.

The patient resumed taking prednisone, and the dosage was increased in order to ameliorate the symptoms of his Crohn's disease.

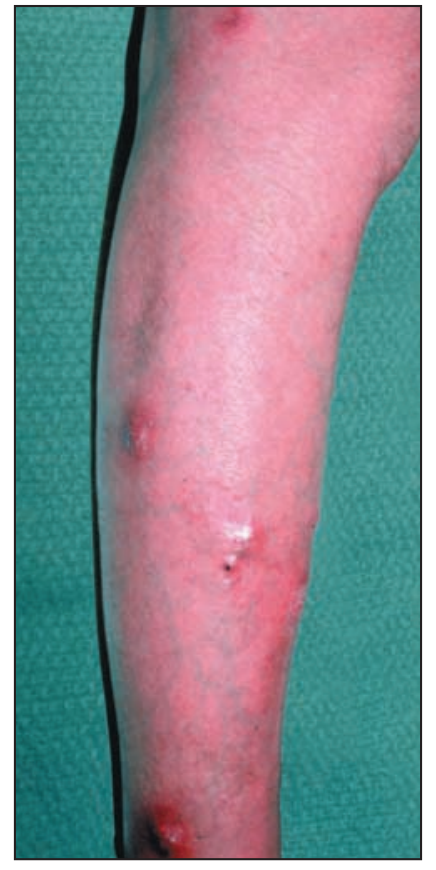

Fig. 1: Multiple erythematous papulopustular lesions on the patient's leg 1 month after the third infusion of infliximab. 
The trimethoprim-sulfamethoxazole therapy was continued until late 2003, and the dosage was reduced over the subsequent months. Complete healing of the lesions was eventually achieved 4 years after therapy was initiated.

\section{Comments}

Infliximab is a chimeric anti-tumour necrosis factor- $\alpha$ $(\mathrm{TNF}-\alpha)$ antibody that is efficacious in treating Crohn's disease. ${ }^{2,3}$ Infectious complications may arise during therapy owing to its immunosuppressive properties. Nocardia is a genus of soil-borne aerobic actinomycetes that may produce local or disseminated infections in immunocompromised people. The breach in skin integrity on the patient's leg may have permitted local invasion by this ubiquitous organism. Defenses against Nocardia species are multifaceted and include a cell-mediated response, ${ }^{4}$ which corticosteroids and infliximab impede. Corticosteroids inhibit the release of chemoattractive factors, decrease the extravasation of leukocytes and inhibit the production of cytokines, including interferon gamma, interleukins and TNF- $\alpha$, which thereby decreases macrophage and T-cell function. ${ }^{5}$ Infliximab binds soluble TNF- $\alpha$ and TNF- $\alpha$ receptors on macrophages and T cells, which results in apoptosis of macrophages and T cells. ${ }^{6}$

A microbiological diagnosis could not be made in this case. Although mycobacterial disease (including tuberculosis) is not excluded by negative polymerase chain reaction results or even by negative tissue cultures for Mycobacteria, the patient's response to sulfonamide therapy would not have occurred had the infection been caused by a mycobacterial pathogen. Moreover, the results of the polymerase chain reaction assay supported the diagnosis of nocardiosis, as did the response to the trimethoprim-sulfamethoxazole therapy. The morphology of the acid-fast bacilli is consistent with, but not specific for, Nocardis species.

The patient did not experience infectious lesions when he was taking prednisone therapy alone; the lesions erupted after the infliximab infusions were initiated. This suggests that infliximab played at least a permissive role in this infection. Clinical experience with infliximab and with corticosteroids

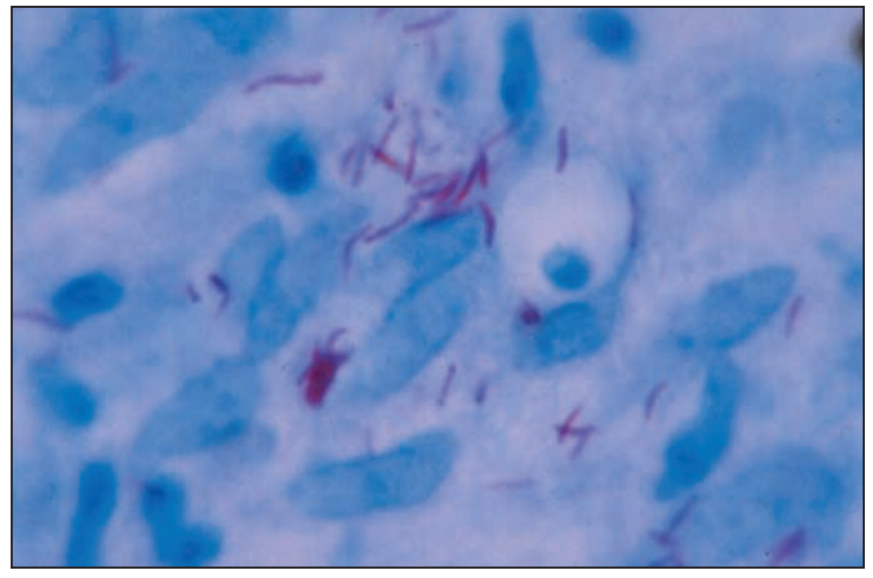

Fig. 2: Acid-fast bacilli visualized in skin biopsy. has demonstrated an increased risk of infections, and this risk may be enhanced with concurrent infliximab and corticosteroid therapy. ${ }^{7}$ To date, listeriosis, ${ }^{6}$ invasive pulmonary aspergillosis, ${ }^{8}$ Pneumocystis jiroveci pneumonia, ohistoplasmosis and coccididomycosis ${ }^{9}$ have been reported in association with infliximab infusions. Our case report suggests that Nocardia infections should be added to the list of potential complications associated with the profound immunosuppression caused by infliximab. Use of other tumour necrosis factor inhibitory agents may also be associated with an increased risk of opportunistic infections. Recently, when etanercept was used to treat alcoholic hepatitis, 1 of 13 patients in the study had disseminated Nocardia infection. The etanercept therapy was discontinued, and the patient survived. ${ }^{10}$

On the basis of our case report, we suggest that discontinuing anti-TNF- $\alpha$ antibody therapy may be necessary for complete resolution of an associated opportunistic infection.

This article has been peer reviewed.

From the Department of Medicine, Sunnybrook and Women's College Health Sciences Centre, University of Toronto, Toronto, Ont. (Singh, Cohen), the Halton Healthcare Services, Oakville, Ont., and the Credit Valley Hospital, Mississauga, Ont. (Rau, Harris)

Competing interests: None declared.

Contributors: All of the authors provided medical care to the patient described in the case report, reviewed the literature on infectious complications associated with infliximab use, were involved in writing the case report and approved the final version submitted for publication.

Acknowledgements: We are grateful to the superb care afforded to this patient by our research nurse, Mary Morgan. We are also grateful to Dr. George Broukhanski (Ontario Public Health Laboratory) for his assistance in the interpretation of the unusual laboratory aspects of this case.

\section{References}

1. Telenti A, Marchesi F, Balz M, Bally F, Bottger EC, Bodmer T. Rapid identification of Mycobacteria to the species level by polymerase chain reaction and restriction enzyme analysis. 7 Clin Microbiology 1993;31(2):173-8.

2. Present DH, Rutgeerts P, Targan S, Hanauer SB, Mayer L, van Hogezand $\mathrm{RA}$, et al. Infliximab for the treatment of fistulas in patients with Crohn's disease. N Engl 7 Med 1999;340(18):1398-405.

3. Sands BE, Anderson FH, Bernstein CN, Chey WY, Feagan BG, Fedorak $\mathrm{RN}$, et al. Infliximab maintenance therapy for fistulizing Crohn's disease. $N$ Engl 7 Med 2004;350(9):876-85.

4. Lerner PI. Nocardiosis. Clin Infect Dis 1996;22:891-905.

5. Schimmer BP, Parker KL. Adrenocorticotrophic hormone; adrenocortical steroids and their synthetic analogs; inhibitors of the synthesis and action of adrenocortical hormones. In: Hardman JG, Limbird LE, editors. Goodman and Gilman's The pharmacological basis of therapeutics. New York: McGraw Hill; 1996. p. 1459-87.

6. Morelli J, Wilson FA. Does infliximab administration increase susceptibility to listeriosis? Am 7 Gastroenterol 2000;95:841-2.

7. Farrell RJ, Shah SA, Lodhavia PJ, Alsahli M, Falchuk KR, Michetti P, et al. Clinical experience with infliximab therapy in 100 patients with Crohn's disease. Am 7 Gastroenterol 2000;95(12):3490-7.

8. Warris A, Bjorenklett A. Invasive pulmonary aspergillosis associated with infliximab [letter]. N Engl f Med 2001;334:1099-100.

9. Keenan GF, Schaible TF, Boscia JA. Reply to: Invasive pulmonary aspergillosis associated with infliximab [letter]. N Engl 7 Med 2001;334:1100.

10. Menon KV, Stadheim L, Kamath PS, Wiesner RH, Gores GJ, Peine CJ, et al. A pilot study of the safety and tolerability of etanercept in patients with alcoholic hepatitis. Am 7 Gastroenterol 2004;99(2):255-60.

Correspondence to: Dr. Lawrence B. Cohen, Sunnybrook and Women's College Health Sciences Centre, Rm. HG 63, 2075 Bayview Ave., Toronto ON M4N 3M5; fax 416 480-5988; lawrence.cohen@sw.ca 